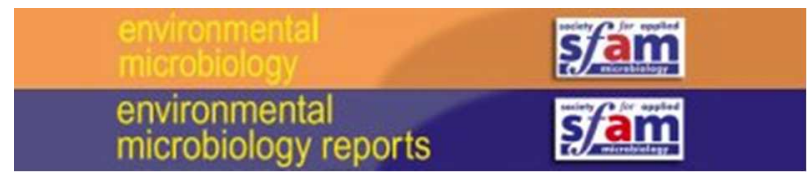

\title{
Zur (FurB) is a key factor in the control of the oxidative stress response in Anabaena sp. PCC 7120.
}

\begin{tabular}{|r|l|}
\hline Journal: & Environmental Microbiology and Environmental Microbiology Reports \\
\hline Manuscript ID: & EMI-2014-0941 \\
\hline Manuscript Type: & EMI - Research article \\
\hline Journal: & Environmental Microbiology \\
\hline Complete List of Authors: & $\begin{array}{l}\text { Sein-Echaluce, Violeta; University of Zaragoza and BIFI, Biochemistry and } \\
\text { Molecular and Cell Biology } \\
\text { González, Andrés; University of Zaragoza and BIFI, Biochemistry and } \\
\text { Molecular and Cell Biology } \\
\text { Napolitano, Mauro; CSIC, Instituto de Bioquímica Vegetal y Fotosíntesis } \\
\text { Luque, Ignacio; CSIC, Instituto de Bioquímica Vegetal y Fotosíntesis, } \\
\text { Barja, Francois; UNIVERSITE DE GENEVE Unité de Microbiologie, } \\
\text { Peleato, Maria Luisa; University of Zaragoza and BIFI, Biochemistry and } \\
\text { Molecular and Cell Biology } \\
\text { Fillat, Maria F.; University of Zaragoza and BIFI, Biochemistry and } \\
\text { Molecular and Cell Biology }\end{array}$ \\
\hline Keywords: & $\begin{array}{l}\text { bacteria, ecophysiology, environmental signal/stress responses, gene } \\
\text { expression/regulation, metabolic networks, metals, microbial genetics }\end{array}$ \\
\hline \hline
\end{tabular}

\section{SCHOLARONE \\ Manuscripts}


3 Zur (FurB) is a key factor in the control of the oxidative stress 4 response in Anabaena sp. PCC 7120.

5 Violeta C. Sein-Echaluce ${ }^{1}$, Andrés González ${ }^{1}$, Mauro Napolitano ${ }^{2}$, Ignacio Luque ${ }^{2}$,

6 Francisco Barja $^{3}$, M. Luisa Peleato ${ }^{1}$ and María F. Fillat ${ }^{1 *}$

7

$8{ }^{1}$ Departamento de Bioquímica y Biología Molecular y Celular, Universidad de 9 Zaragoza, 50009 Zaragoza, Spain; Instituto de Biocomputación y Física de Sistemas 10 Complejos (BIFI), Universidad de Zaragoza, 50009 Zaragoza, Spain.

$11{ }^{2}$ Instituto de Bioquímica Vegetal y Fotosíntesis, CSIC-Universidad de Sevilla, E-41092 12 Sevilla, Spain.

$13{ }^{3}$ Microbiology Unit, Botany and Plant Biology Dept., University of Geneva, Ch. Des 14 Embrouchis 10, CH-1254 Jussy-Geneva, Switzerland.

15

16
* For correspondence: María F. Fillat. Department of Biochemistry and Molecular and Cell Biology. Faculty of Sciences. University of Zaragoza. Pedro Cerbuna, 12. 50009Zaragoza, Spain; Tel. (+34) 976761282; Fax (+34) 976762123. E-mail fillat@unizar.es.

Running title: Role of Zur in the oxidative stress response in Anabaena 
32 Iron and zinc are necessary nutrients whose homeostasis is tightly controlled by members of the FUR superfamily in the cyanobacterium Anabaena sp. PCC7120.

34 Although the link between iron metabolism and oxidative stress management is well 35 documented, little is known about the connection between zinc homeostasis and the 36 oxidative stress response in cyanobacteria. Zinc homeostasis in Anabaena is controlled 37 by Zur, the FurB paralogue. When overexpressed in Escherichia coli, Zur (FurB) 38 improved cell survival against oxidative stress. Zur also protected DNA against 39 hydroxyl radical damage in vitro. In order to investigate the possible correlation 40 between Zur and the oxidative stress response in Anabaena, zur deletion and zur41 overexpressing strains have been constructed and the consequences of Zur imbalance 42 evaluated. The lack of Zur increased sensitivity to $\mathrm{H}_{2} \mathrm{O}_{2}$, whereas an excess of Zur 43 enhanced oxidative stress resistance. Both mutants displayed pleiotropic phenotypes, 44 including alterations on the filament surfaces observable by scanning electron 45 microscopy, reduced content of endogenous $\mathrm{H}_{2} \mathrm{O}_{2}$ and altered expression of sodA, 46 catalases and several peroxiredoxins. Transcriptional and biochemical analyses unveiled 47 that the appropriate level of Zur is required for proper control of the oxidative stress 48 response and allowed us to identify major antioxidant enzymes as novel members of the 49 Zur regulon. 


\section{INTRODUCTION}

52

Reactive oxygen species (ROS) are unavoidable by-products of aerobic metabolism that can damage several cellular sites including iron-sulfur clusters, cysteine and methionine protein residues, lipids and DNA (Chiang and Schellhorn, 2012). The generation of toxic radicals is enhanced by a source of biometals including iron and zinc that, at the same time, are essential nutrients for the vast majority of organisms (Stohs and Bagchi, 1995). Iron is a constituent of a wide range of proteins involved in photosynthesis, respiration, nitrogen metabolism, defense against oxidative stress, DNA biosynthesis and gene regulation, among others (Cornelis and Andrews, 2010). In spite of being the fourth most abundant element in the Earth's crust, the high reactivity of ferric iron with oxygen to form insoluble oxides and hydroxides, makes this nutrient scarcely bioavailable (Andrews et al., 2003). Unlike iron, zinc is only a trace metal in the Earth's crust. Nevertheless, zinc is involved in a huge number of biological processes and its chemical properties make this metal a staple part of many proteins and enzymes, where it plays structural, catalytic or regulatory roles. Although under physiological conditions zinc is not a redox active metal, its capacity to bind and to protect free sulfhydryl groups in proteins as well as the involvement of zinc proteins in the biosynthesis of low molecular weight thiols links zinc homeostasis to the maintenance of the intracellular redox status (Ma et al., 2009; Eide, 2011). Furthermore, the occurrence of a variety of redox zinc switches coupled to thiol/disulphide exchanges enables a connection between redox status and zinc metabolism (Maret, 2006). While iron toxicity lies in the ability of this metal to effectively catalyze the Fenton reaction, zinc toxicity has been attributed to its propensity to interact adventitiously with thiol groups of many proteins, especially those involved in electron transport (Mills et al., 2002). Consequently, metal concentrations inside the cells must be finely tuned not only for adjusting metal uptake 
77 to cell requirements, but also for keeping redox homeostasis in order to minimize 78 oxidative stress. In prokaryotes, this control is carried out by different families of 79 metalloregulators, which act in a coordinated way regulating metal homeostasis and 80 preventing cell oxidative damage (Ma et al., 2009). One of the most important families 81 of metalloregulators is constituted by the FUR (Ferric Uptake Regulator) proteins that 82 can be divided into different functional classes according to the signal they sense: Fur 83 (iron sensing proteins), Zur (zinc), Mur (manganese) and Nur (nickel). The PerR and Irr 84 subfamilies, which also belong to the FUR family, sense oxidative stress and haem 85 levels, respectively (Lee and Helmann, 2007).

86 Because of their photosynthetic metabolism, iron requirements of cyanobacteria are 87 much larger than those of heterotrophic microorganisms (Shcolnick et al., 2009). On the other hand, the generation of reactive oxygen species by fortuitous electron transfer to oxygen during the photosynthetic process enhances the risk of damage to iron-sulfur clusters compromising cyanobacterial metabolism. Accordingly, metal homeostasis mechanisms and the oxidative stress defenses are tightly coordinated in cyanobacteria, where FUR proteins play major role. Anabaena sp. PCC 7120 is a nitrogen-fixing cyanobacterium that in the absence of combined nitrogen is able to differentiate heterocysts distributed semi-regularly in the filament (Flores and Herrero, 2010). The genome of Anabaena sp. PCC 7120 encodes three FUR proteins, previously named as FurA, FurB and FurC (Hernandez, 2004).

97 FurA is the master regulator of iron homeostasis and couples iron status with both 98 nitrogen metabolism and the oxidative stress response (Lopez-Gomollon et al., 2007b; Lopez-Gomollon et al., 2007a; Gonzalez et al., 2010; González et al., 2011; González et al., 2012). FurC has been identified as a PerR protein in Anabaena sp. PCC 7120

101 (Yingping et al., 2014), while FurB controls zinc homeostasis acting as a Zur protein 
102 (Napolitano et al., 2012). Zur (FurB) binds to DNA in a zinc-dependent manner and 103 represses transcription of target genes under zinc-sufficient conditions. Zur controls a 104 regulon which includes genes encoding putative metallochaperones (e.g. All4722, 105 All1751), paralogues of zinc metalloproteins (e.g. All4725/HemE, All4723/ThrS), 106 components of plasma membrane ABC transport systems (e.g. ZnuABC), and several 107 outer membrane proteins (e.g. Alr3242, Alr4028) (Napolitano et al., 2012). Similar 108 targets have been found or predicted to be regulated by Zur in other cyanobacteria 109 (Barnett et al., 2012) as well as in non-photosynthetic bacteria, such as Escherichia coli 110 (Patzer, 2000), Staphylococcus aureus (Lindsay and Foster, 2001), Bacillus subtilis 111 (Fuangthong and Helmann, 2003) and Mycobacterium tuberculosis (Maciag et al., 112 2006), among others.

113 Besides its role as a metal regulator, Zur from Anabaena sp. has been shown to enhance 114 cell survival under oxidative stress conditions when it is overexpressed in E. coli. In 115 addition, in vitro assays have shown the ability of this protein to unspecifically bind 116 DNA, protecting it against both, oxidative damage and DNaseI digestion (López117 Gomollón et al., 2009). Hence, a dual role for Anabaena sp. Zur has been previously suggested depending on the protein concentration into the cell. At low concentrations, Zur works as a transcriptional regulator binding to the promoters of target genes in a specific manner. At higher concentrations of the protein, maybe induced by oxidative stress, Zur would bind unspecifically to DNA, protecting it from oxidative damage 122 (López-Gomollón et al., 2009).

123 Correlation between oxidative stress and iron starvation has been well established in cyanobacteria (Latifi et al., 2005; Shcolnick et al., 2009). However, the elements linking zinc homeostasis to oxidative stress management by the cell remain to be identified. In this study, the molecular bases of the connection between Zur and the oxidative stress 
127 response have been investigated. Our analyses of the phenotypes of two Anabaena sp.

128 derivative strains, a zur deletion mutant and a zur-overexpressing strain, show that

129 changes in zur expression levels deeply affect cyanobacterial phenotype, including

130 alterations in septum morphology and the organization of the outmost cell layers,

131 among other features. Transcriptional and biochemical assays led to the identification of

132 key genes involved in the oxidative stress response as novel members of the Zur

133 regulon. Those results establish a direct connection between the control of zinc

134 metabolism and the regulation of the antioxidant defenses in Anabaena sp. PCC 7120.

RESULTS

137

$\triangle$ ür and zur overexpressing mutants of Anabaena sp. PCC 7120 exhibit a pleiotropic phenotype

To achieve a better understanding of the alternative functions of Zur in Anabaena sp., a zur overexpressing strain (VCS2770) was generated and its phenotype evaluated in comparison with those from a zur deletion mutant $(\Delta z u r)$ and the parental wild type Anabaena sp. PCC 7120. Photoautotrophic growth under standard culture conditions of $\Delta z u r$ was slower than that observed in the wild type strain (doubling time 10 days versus 8.4 days). Conversely, the zur-overexpressing strain VCS2770 doubled in only 7.8 days. (Figure 1). Despite the zur-overespressing strain exhibited higher chlorophyll content than $\Delta z u r$ and the wild type control, photosynthetic and respiratory activities were similar in the three Anabaena strains. (Table 2).

Cyanobacterial morphology of exponentially growing cultures was visualized using different microscopy techniques. Bright-field and fluorescence microscopy analyses showed that there were not noticeable differences in filament length and intrinsic 
152 fluorescence between the wild type and the derivative strains. Under absence of 153 combined nitrogen $\left(\mathrm{BG} 11_{0}\right)$, cultures of $\Delta z u r$ and VCS2770 strains displayed similar 154 heterocyst development patterns than those observed in Anabaena sp. PCC 7120 (data 155 not shown). However, scanning electron microscopy (SEM) analyses showed that $\Delta z u r$ 156 cells displayed a different shape and appeared to be connected by narrower septa 157 compared to Anabaena sp. PCC 7120 and VCS2770 (Figure 2A). A severe disruption of $158 \Delta z u r$ filaments after treatment for transmission electron microscopy (TEM) studies in comparison to Anabaena wild type and VCS2770 strains was also observed (not shown). Those features, as well as the release of phycobiliproteins of the photosynthetic antenna in $\Delta z u r$ when cultures were left to decant overnight without bubbling (Fig. 2B) could be indicative of a more fragile junction between cells. On the other hand, the cell surface of the VCS2770 strain was visibly affected (Figure 2A), suggesting that not only the slime sheath enclosing filaments might be influenced by zur overexpression, but also the organisation of the outer membrane.

Oxidative stress tolerance in Anabaena sp. is strongly influenced by Zur expression levels

Prior to the identification of FurB as a Zur regulator in Anabaena sp., it was found that overexpression of FurB/Zur in E. coli increased its tolerance to ROS (López-Gomollón et al., 2009). In the present study, we sought to investigate whether the expression levels

171 of Zur could influence tolerance to oxidative stress imposed by exogenous hydrogen peroxide $\left(\mathrm{H}_{2} \mathrm{O}_{2}\right)$ in Anabaena cells. As shown in Figure 3, the Anabaena sp. strain lacking Zur was much more sensitive to oxidative challenge than its parental strain. In contrast, Zur overexpression increased cyanobacterial tolerance to hydrogen peroxide as it was observed when this protein was overproduced in E. coli. 
$\triangle z u r$ and VCS2770 derivative strains exhibit altered superoxide dismutase (SOD) and catalase activities, as well as diminished $\mathrm{H}_{2} \mathrm{O}_{2}$ contents

To gain more insights about the mechanism underlying tolerance to $\mathrm{H}_{2} \mathrm{O}_{2}$, SOD and catalase activities, as well as the endogenous content of $\mathrm{H}_{2} \mathrm{O}_{2}$ were measured in the three cyanobacterial strains. As shown in Fig. 4, the $\Delta z u r$ strain showed increased SOD and catalase activities (about 120\% and 156\%, respectively) compared to Anabaena sp. PCC 7120. However, catalase activity appeared diminished in the zur-overexpressing strain VCS2770 compared to the Anabaena sp. wild type (70\%), while SOD activities were similar in both strains. Surprisingly, the amount of endogenous $\mathrm{H}_{2} \mathrm{O}_{2}$ dropped dramatically in both, $\Delta z u r$ and VCS2770 Anabaena strains, whose values were less than $10 \%$ of this from the parental Anabaena sp. control (Figure 5). Those results suggest that the reduction in the amount of endogenous $\mathrm{H}_{2} \mathrm{O}_{2}$ in $\Delta z u r$ and VCS2770 strains takes place through different pathways.

\section{Changes in Zur levels affects the Anabaena sp. oxidative stress response machinery}

These results prompted us to investigate a potential connection of Zur with the transcription of main genes related to oxidative stress tolerance. Genes under study were the two Mn-catalases (alr0998 and alr3090) encoded by Anabaena sp. PCC 7120, superoxide dismutases and peroxiredoxins $\operatorname{prx} A, \operatorname{gct} 1$ and $\operatorname{gct} 3$. Since FurB/Zur was previously described as a DNA protecting protein (López-Gomollón et al., 2009), transcription of several genes coding for DNA-binding proteins related to the oxidative stress response, namely $d p s A$, hanA and all4145 (probable DNA-binding stress protein) was also analysed. Finally, because of the implication of furA and furC (perR) in cyanobacterial redox homeostasis, the influence of zur expression in these paralogs was investigated. Changes in mRNA levels were determined by semi-quantitative reverse 
transcription-PCR (RT-PCR), as described previously (González et al., 2012). To obtain

201 accurate data, determinations for each gene were performed at the early exponential phase of the PCR. The $r n p B$ housekeeping gene was included in all RT-PCR analyses to ensure that equivalent amounts of total RNA were being used in all reactions. As shown in Figure 6 and table 3, transcription of furA was up-regulated in the absence of Zur, while furA expression appeared down-regulated in the VCS2770 strain. Since the final expression of furA in Anabaena is modulated by an antisense RNA (Hernandez et al., 2006), Western analyses were performed to verify that the amount of FurA in Anabaena showed an inverse correlation to zur expression levels (data not shown).

Transcription of $\operatorname{sod} A$ and catalase alr0998 was strongly enhanced in $\Delta z u r$. A different pattern was observed with catalase alr3090, whose transcription was higher in the wild type and the VCS2770 strains. The expression of peroxiredoxin gct3 was also significantly higher in $\Delta z u r$, whereas gctl expression was affected in a similar way in the two Anabaena mutants, suggesting that other proteins, in addition to Zur, are involved in its regulation. Finally, $\operatorname{prxA}$ appeared downregulated in a zuroverexpressing background. Regarding transcription of the DNA-binding proteins tested, only a slight change was observed in the $d p s A$ levels, while no significant differences were appreciated in the transcription of hanA and all4145 among the three cyanobacterial strains.

\section{Zur regulates key genes involved in the oxidative stress response in Anabaena sp.}

221 In order to discern which of the genes whose transcription levels appeared strongly 222 influenced by Zur were direct targets of this regulator, EMSA analyses were performed 223 in the presence of the unspecific control DNA $\mathrm{P}_{\text {nifJ. }}$. The all4725 promoter, where Zur has been found to bind with high affinity, was used as control (Napolitano et al., 2012). 
225 The results shown in Fig. 7 indicate that Zur recognises Mn catalase alr0998, sodA and $226 \operatorname{prxA}$ promoters. Binding of Zur to catalase alr3090 and peroxiredoxin gct3 promoters

227 was much fainter. It is also noteworthy that binding of Zur to those promoters did not 228 yield gel defined DNA-protein complexes as in the case of the binding to all4725 229 promoter, indicating a lower affinity of Zur for those oxidative stress related gene 230 promoters.

\section{DISCUSSION}

233

234

In addition to controlling zinc homeostasis, zinc-responsive factors have also been shown to regulate the expression of genes than can be critical for an organism to survive, such as those involved in the oxidative stress defense (Choi and Bird, 2014). Despite the increasing evidences relating alterations in zinc metabolism to increased levels of oxidative stress (Bonet et al., 2012; Graham et al., 2012; Choi and Bird, 2014; Eijkelkamp et al., 2014), the potential participation of Zur in this process remains to be uncharacterized. Beyond the control of zinc homeostasis, Zur from Anabaena sp. PCC 7120 has been proposed to protect $E$. coli cells by direct interaction with DNA, similarly to Dps proteins. In this work, the potential implication of Zur in the oxidative stress response in Anabaena sp. PCC 7120 has been investigated. Analyses of the phenotypes of $\Delta z u r$ and zur-overexpressing (VCS2770) strains in combination with transcriptional and EMSA assays led us to identify some of the molecular basis of the protective effect of Zur against oxidative stress in Anabaena sp. PCC 7120. The lack of Zur delayed cyanobacterial growth under standard culture conditions. The impairing in photoautotrophic growth of the $\Delta z u r$ strain in BG-11 medium supplemented with 25 $\mu \mathrm{M}$ zinc sulphate has been previously observed (Napolitano et al., 2012). Our results showed that the growth of this strain is diminished even in BG-11 medium $(0.77 \mu \mathrm{M}$ 
250 zinc). In the absence of Zur, de-regulation of the machinery involved in the control of

251 zinc uptake likely leads to the increase of intracellular free zinc. This metal can interact

252 with thiol groups of proteins, blocking the binding of other metals and thus impairing

253 essential reactions, especially in electron transport systems (Mills et al., 2002).

254 Conversely, doubling time of the VCS2770 strain was similar to that of the wild type.

255 The increased expression of Zur, around 5 times of the value found in Anabaena sp.

256 PCC 7120, might not be enough for a complete repression of target genes.

257 Alternatively, an over-repression of the Zur regulon could led to the use of unspecific or

258 low affinity transporters (Panina et al., 2003; Gabriel and Helmann, 2009; Sankaran et

259 al., 2009). The morphological differences observed in the filaments of those strains with

260 respect to Anabaena sp. PCC 7120, namely alteration of cell septum and cell surface in

$261 \Delta z u r$ and VCS2770 respectively, could be caused in part by the misregulation of Zur

262 targets encoding outer-membrane proteins (e. g. the TonB-dependent receptors Alr3242

263 and Alr4028), among other unidentified causes. The mreBCD operon, which encodes

264 for the bacterial actin MreB and the cell wall synthetic proteins MreC and MreD, plays

265 a critical role in the determination of cell morphology in several species of bacteria

266 (Singh and Montgomery, 2011). Since the interaction between TonB-dependent

267 receptors (TBDRs) and MreC has been previously reported in Caulobacter crescentus

268 (Divakaruni et al., 2005), misregulation of TBDRs could lead in an indirect way to the

269 alteration of cell morphology. Curiously, the mreBCD operon is a direct target of FurA

270 in Anabaena sp. PCC 7120 and alterations in FurA levels also induced changes in the

271 Anabaena sp. cell morphology (Gonzalez et al., 2010).

272 Photosynthetic oxygen evolution and respiration measurements gave similar values in

273 the three strains though VCS2770 displayed higher chlorophyll $a$ content. Probably, the

274 "extra" chlorophyll present in this strain could be mainly bound to peripheral antenna 
275 proteins. Those data, together with the transcription patterns of sod genes and the lower

276 expression of furA in VCS2770 suggest that overexpression of Zur might enhance iron 277 uptake in Anabaena.

278 Anabaena sp. PCC 7120 contains a wide range of enzymes directly involved in the 279 oxidative stress response including two superoxide dismutases, two catalases, several 280 peroxiredoxins and Dps proteins, among others (Latifi et al., 2009; Banerjee et al., 2013). Our experiments revealed interesting differences in the global catalase activity of strains with different levels of expression of Zur, as well as an altered pattern of expression of catalases Alr0998 (Banerjee et al., 2012) and Alr3090/KatB (Bihani et al., 2013). Global catalase activity was significantly higher in the $\Delta z u r$ strain, in consonance with the strong transcriptional induction of alr0998 in this mutant. Therefore, the increased expression of catalase alr0998 and the increase in global catalase activity in the $\Delta z u r$ strain could explain its low concentration of intracellular $\mathrm{H}_{2} \mathrm{O}_{2}$. It is remarkable that, in spite of having decreased catalase activity, the VCS2770 strain exhibited even a lower content of intracellular hydrogen peroxide and the highest tolerance against exogenous $\mathrm{H}_{2} \mathrm{O}_{2}$. Those results suggest that this strain was subjected to lower oxidative stress and, hence, the requirement for catalase was lower. Similar 292 results were reported when FurA was overexpressed in Anabaena sp. PCC 7120. A raise in FurA expression down-regulated antioxidant activities in cyanobacterium but did not lead to an oxidative stress situation (Gonzalez et al., 2010). In addition to these two catalases, the genome of Anabaena sp. PCC 7120 encodes two peroxidases, namely Alr1585 and Alr0672, which could account for detoxification of $\mathrm{H}_{2} \mathrm{O}_{2}$ in VCS2770, 297 though other alternative pathways related to the excess of Zur cannot be discarded. 298 These results are in good agreement with the hypothesis that Zur acts as a protective 299 protein by itself when present at high concentrations (López-Gomollón et al., 2009). 
300 Whether Zur works as a Dps protein in Anabaena or alleviates oxidative stress taking

301 part in an alternative electron transport chain is an interesting issue that deserves to be 302 investigated.

303 Semi-quantitative RT-PCR analyses of other major genes involved in the concerted 304 response against oxidative stress led us to identify novel putative targets for Zur, 305 namely $\operatorname{sod} A$, peroxiredoxins $\operatorname{prxA}, \operatorname{gct} 1$ and $g c t 3$, and the stress-induced DNA-binding 306 protein $\operatorname{dps} A$ (alr3808). The analysis of transcriptional patterns and EMSA assays 307 allowed us to discriminate different groups of genes according to the effect of Zur on their control. Zur seems to play a key role in the direct transcriptional repression of $\operatorname{sodA}$, catalase alr0998 and peroxiredoxin gct3. While the de-repression of alr0998 in

$310 \Delta z u r$ is in good concordance with the increase of catalase activity, the strong induction 311 of the $\operatorname{sod} A$ transcript in $\Delta z u r$ contrasts with the moderate differences between the 312 values of superoxide dismutase activity observed in the three strains. Manganese is a 313 required cofactor for SodA activity. As it has been observed in Streptococcus 314 pneumoniae (Eijkelkamp et al., 2014), the excess of zinc likely present in $\Delta z u r$ could 315 compromise manganese uptake in Anabaena. Consequently, Mn deficit would impair 316 the assembly of the total induced apoprotein to yield fully active holo-SodA. 317 Consistently with EMSA results, the promoter regions of this group of genes contain 318 multiple AT-rich regions that partially match with the Zur consensus sequence 319 described previously (Napolitano et al., 2012). A different set of genes is composed by $320 \operatorname{prx} A$ and $\operatorname{dps} A$ that are mildly repressed by an excess of Zur (VCS2770 strain) that 321 binds to their promoters. However, their transcription levels in $\Delta z u r$ were similar to 322 those in the wild type Anabaena sp. strain, indicating that $\operatorname{prx} A$ and $\operatorname{dps} A$ are modulated 323 by additional regulatory factors, including other FUR paralogs (Hernandez et al., 2007; 324 Yingping et al., 2014). Co-regulation of Zur with other regulatory proteins has also been 
reported in heterotrophic bacteria (Kallifidas et al., 2009). Finally, RT-PCR analyses suggest that Zur modulates catalase alr3090 indirectly, since its binding to this promoter is very poor.

Regulation of FurA from Anabaena sp. is a rather complex process that is controlled at every single step in the flow of genetic information (Botello-Morte et al., 2013). The expression pattern of furA in both mutant strains confirms that Zur participates directly in this regulation. Binding assays to the furA promoter carried out in this work and in previous studies (Hernandez, 2004) support that hypothesis. The furA promoter also contains two AT-rich regions partially matching with the consensus sequence described for Zur. However, these boxes are distant from the transcription start sites (-52 bp and $115 \mathrm{bp)}$ and furA expression is not fully repressed in the VCS2770 mutant, suggesting that Zur might be just a mild repressor of furA. An analogous expression pattern is observed in a furA overexpressing mutant, where the expression of Zur is severely decreased (Gonzalez et al., 2010). Those data support our previous results suggesting an inter-regulation between those two members of the Fur family in Anabaena sp. PCC 7120 (Hernandez, 2004).

Previous reports demonstrate that FurA also participates in the control of metal homeostasis and the oxidative stress response. FurA has been shown to directly regulate peroxiredoxins Alr4641/PrxA and Al11541, and the DpsA protein (Hernandez et al., 2007; González et al., 2011). Regulation by Fur of genes involved in redox homeostasis has been also found in heterotrophic bacteria (Hassan and Sun, 1992; Hasset et al., 1997; Lee et al., 2004; Li et al., 2009). Our in vivo and in vitro assays unveil that Zur plays a key role in the control of the oxidative stress response in Anabaena sp. PCC 7120. The identification of novel Zur-regulated genes in this cyanobacterium sheds some light on the elements linking zinc homeostasis with oxidative stress management 
350 in Anabaena sp. PCC 7120, showing an interesting overlap between the FurA and Zur

351 regulons. In summary, those results evidence that Zur is a multifunctional regulatory

352 protein that connects zinc metabolism to oxidative stress management in Anabaena sp.

353 PCC 7120.

354 EXPERIMENTAL PROCEDURES

355

356

\section{Bacterial strains and culture conditions}

357 Bacterial strains used in this study are described in Table S1. Anabaena sp. PCC 7120, the zur-overexpressing derivative mutant VCS2770 and the deletion-insertion mutant $\Delta z u r$ were grown photoautotrophically in BG-11 medium (Rippka et al., 1978) at $28^{\circ} \mathrm{C}$ 360 under a constant illumination of $50 \mu \mathrm{E} \mathrm{m}^{-2} \mathrm{~s}^{-1}$. Culture medium was supplemented 361 with neomycin $50 \mu \mathrm{g} \mathrm{ml}{ }^{-1}$ for strain VCS2770 and with streptomycin and 362 spectinomycin 2-5 $\mu \mathrm{g} \mathrm{ml}^{-1}$ for strain $\Delta z u r$. Cultures were performed using Erlenmeyer 363 flasks at a constant shaking of 120 r.p.m.

364 Escherichia coli strains used for cloning procedures were grown at $37^{\circ} \mathrm{C}$ in Luria365 Bertani medium, supplemented with the appropiated antibiotics at the following 366 concentrations: kanamycin $50 \mu \mathrm{g} \mathrm{ml}^{-1}$, ampicillin $50 \mu \mathrm{g} \mathrm{ml}^{-1}$, chloramphenicol $30 \mu \mathrm{g}$ $367 \mathrm{ml}^{-1}$, streptomycin $25 \mu \mathrm{g} \mathrm{ml}^{-1}$ and spectinomycin $100 \mu \mathrm{g} \mathrm{ml}^{-1}$.

Construction of the Anabaena sp. PCC 7120 derivative strains

370 The zur deletion-insertion strain was described elsewhere (Napolitano et al., 2012). The 371 zur-overexpressing strain was constructed as follows. Chromosomal DNA was 372 extracted from Anabaena sp. PCC 7120 (Cai and Wolk, 1990) and used as a template to 373 amplify the zur gene, using primers 2770FurB_up and 2770FurB_dw (Table S2). These 374 primers contained the restriction sites for BamHI and NdeI enzymes, so that the PCR 375 product was double digested and cloned into those restriction sites in the pAM2770 
376 shuttle vector (Lee et al., 2003). The resulting plasmid, pAM2770::zur, contained the

377 zur gene downstream the petE promoter, which is inducible by copper (Buikema and 378 Haselkorn, 2001). The construction was sequenced to verify that the cloning procedure 379 was successful. Plasmid pAM2770::zur was transferred to Anabaena sp. PCC 7120 by 380 triparental mating (Elhai et al., 1997). Three exconjugant clones were cultured in BG-11 381 medium to an optical density of 0.5 at $750 \mathrm{~nm}$ and then collected to test the 382 overexpression of Zur by Western blot (Figure S1). As previously described, the 383 amount of copper in BG-11 medium was enough to activate the petE promoter 384 (Gonzalez et al., 2010). Therefore, no additional copper was added to enhance the overexpression of zur. Finally, the exconjugant clone with the highest expression of zur was selected as the zur-overexpressing strain, named VCS2770.

387

\section{Cyanobacterial growth and pigment measurements}

In order to analyze cyanobacterial growth, all strains were cultured in Erlenmeyer flasks and the optical density was measured at $750 \mathrm{~nm}$ every 2-3 days during 40 days. Growth parameters such as the specific growth rate and doubling time were calculated as previously described (Stein, 1973). Measurements were carried out using a Cary 100 Bio UV-visible spectrophotometer (Varian).

Quantification of photosynthetic pigments and total protein content was performed in cultures at the exponential phase of growth. Chlorophyll $a$ (Nicolaisen et al., 2008), phycobiliproteins (Glazer, 1976) and carotenoids (Davies, 1976) were quantified as previously described. Total protein content was determined by using the bicinchoninic acid protein assay (Pierce). Pigment and protein content were expressed as micrograms per microliter of packed cell volume $(\mathrm{PCV})$, where the $\mathrm{PCV}$ was determined by tube. 


\section{Photosynthetic and respiratory activities}

404

Photosynthetic and respiratory activities were measured in exponentially growing cells

with a Clark type electrode (Oxylab model by Hansatech) at $21^{\circ} \mathrm{C}$ and a constant

shaking of $65 \%$. Photosynthetic activity was determined by measuring the oxygen rate

at light saturating conditions $\left(400 \mu \mathrm{E} \mathrm{m}^{-2} \mathrm{~s}^{-1}\right)$, while the respiratory activity was

determined at dark conditions, covering the electrode chamber with an aluminum paper.

Data were processed with the provided Hansatech software and the results were expressed as $\mathrm{nmol} \mathrm{O} \cdot \mathrm{ml}^{-1} \cdot \mathrm{min}^{-1} \cdot \mathrm{mg} \mathrm{Chla}^{-1}$.

Purification of Zur and Western blot analyses

To obtain the recombinant Zur protein, the $z u r$ gene was amplified using all2473N-2 and all2473C primers described in Table S2 and cloned between the NdeI and HindIII sites of plasmid pET $28 \mathrm{a}(+)$. The resulting His-tagged protein was purified using a zinc affinity column (Matrix Chelating Sepharose ${ }^{\mathrm{TM}}$ Fast Flow, Amersham) and conserved in a $100 \mathrm{mM} \mathrm{NaH} \mathrm{PO}_{4}, 300 \mathrm{mM} \mathrm{NaCl} \mathrm{pH} 6$ solution. For Western blot analysis, cyanobacterial liquid cultures were collected by centrifugation at $4{ }^{\circ} \mathrm{C}$ and cells were resuspended in cold phosphate buffer $50 \mathrm{mM} \mathrm{pH} 8$. The suspension was sonicated five times during 45 seconds with cooling intervals of 30 seconds and then centrifuged to remove cell debris. Protein concentration in crude extracts was determined by using the bicinchoninic acid method (BCA ${ }^{\mathrm{TM}}$ Protein Assay Kit, Thermo Fischer Scientific). For each sample, 10-30 micrograms of total proteins were loaded and separated by electrophoresis with $17 \%$ SDS-PAGE gels. Proteins were transferred to a PVDF membrane $\left(0.45 \mu \mathrm{m}\right.$ pore size Immobilon ${ }^{\circledR}$ transfer membrane from Millipore) and

427 immunodetection was carried out using rabbit polyclonal antibodies raised against Zur. 
430 Fifty milliliters of each cyanobacterial culture were collected by centrifugation and cells

431 were resuspended in one milliliter of phosphate buffer $50 \mathrm{mM} \mathrm{pH} 8$. The cell 432 suspension was sonicated and then centrifuged to remove cell debris. Protein 433 concentration in the extract was quantified by using the BCA method and antioxidant 434 activities were immediately determined. Catalase activity was determined as decribed 435 previously (Beers and Sizer, 1952), following the hydrogen peroxide dissociation by 436 measuring the optical density at $240 \mathrm{~nm}$. Breafly, 300-600 micrograms of protein 437 extract were rapidly mixed in a quartz cuvette with hydrogen peroxide to a final 438 concentration of $20 \mathrm{mM}$. The reaction was followed spectrophotometrically at $240 \mathrm{~nm}$ 439 with a Cary 100 Bio (Varian) device during five minutes. Catalase activity was 440 expressed as Units per milligram of total proteins, defining a Unit as the amount of 441 enzyme that catalyzes the dissociation of 1 microgram of hydrogen peroxide per minute. 442 Superoxide dismutase (SOD) activity was determined by a modification of the method 443 by Winterbourn (Winterbourn et al., 1975), which is based on the ability of SOD to 444 inhibit the reduction of nitro-blue tetrazolium (NBT) by superoxides. Reaction mixtures 445 contained 600 micrograms of protein extract, $6.4 \mathrm{mM}$ EDTA, $41 \mu \mathrm{M} \mathrm{NBT}, 2.3 \mu \mathrm{M}$ 446 riboflavin and $23.5 \mu \mathrm{M}$ TEMED. The control of the assay, with a maximum NBT 447 reduction, contained phosphate buffer instead of the protein extract. Optical density at $448560 \mathrm{~nm}$ was measured before and after illuminating the mixtures for 10 minutes with 449 UV light. Superoxide dismutase activity was expressed as Units per milligram of total 450 proteins, defining a Unit as the amount of enzyme that inhibited the maximum reduction 451 in a $50 \%$.

\section{Endogenous hydrogen peroxide measurement}

454 Intracellular hydrogen peroxide was determined in the cyanobacterial strains using the 455 ferrithiocyanate method (Thurman et al., 1972). Fifty milliliters of each culture were 
456 collected to obtain 50-100 milligrams of fresh cells. Trichloroacetic acid (TCA) at a

457 final concentration of $5 \%$ was added to the cells and the mixture was centrifuged to 458 remove cell debris. 800 microliters of the supernatant were mixed in a plastic cuvette 459 with $160 \mu \mathrm{l}$ of $\mathrm{Fe}\left(\mathrm{NH}_{4}\right)_{2}\left(\mathrm{SO}_{4}\right)_{2} 10 \mathrm{mM}$ (1.3 mM final concentration), $80 \mu \mathrm{l}$ of KSCN $4602.5 \mathrm{M}(167 \mathrm{mM}$ final concentration) and $160 \mu \mathrm{l}$ of TCA $50 \%$. The absorbance at 480 $461 \mathrm{~nm}$ was measured using a Cary 100 Bio spectrophotometer (Varian) to determine the 462 hydrogen peroxide content.

463

464

465

466

467

468

469

470

471

472

473

474

475

476

477

478

479

480

481

\section{Hydrogen peroxide tolerance assay}

To test the tolerance of the cyanobacterial strains to hydrogen peroxide, filaments were exposed to increasing concentrations of hydrogen peroxide for 24 hours. Cultures with an approximate optical density of 1.0 at $750 \mathrm{~nm}$ were washed once with fresh BG-11 medium and $200 \mu \mathrm{l}$ of culture were displayed into each well of a microtiter plate. Hydrogen peroxide was added to the wells at a final concentration of $0,0.5,0.7,1$ and $1.3 \mathrm{mM}$. The plate was incubated for 24 hours in dark conditions and $28^{\circ} \mathrm{C}$. Chlorosis was estimated by reading the absorbance at $620 \mathrm{~nm}$ with a Multiskan EX microplate photometer (Thermo Fischer Scientific).

\section{Microscopy}

Bright-field and fluorescence microscopy analysis of exponentially growing cells were carried out using a Nikon Eclipse 50i Epi-fluorescence microscope coupled to a Nikon DXM 1200F camera. For scanning electron microscopy, cells were harvested at the exponential phase of growth and fixed with $2.5 \%$ glutaraldehyde in phosphate buffer (66 mM NaH $2 \mathrm{PO}_{4} .2 \mathrm{H}_{2} \mathrm{O}, 66 \mathrm{mM} \mathrm{KH}_{2} \mathrm{PO}_{4}, \mathrm{pH}$ 7) for $1 \mathrm{~h}$ at room temperature, washed three times for 5 min each in phosphate buffer, fixed with $2 \% \mathrm{OsO}_{4}$ and washed three 
482 times for 5 min each in distilled water. Scanning electron microscopy was performed in 483 a SEM JEOL JSM 7001FA. Pictures were processed using the Photoshop 6.0 program.

484

485

486

487

496

Semi-quantitative reverse transcription (RT-PCR)

Total RNA was isolated from exponentially growing cultures as previously described (Olmedo-Verd et al., 2005) and residual DNA was removed by treating the samples with RNAse-free DNAseI (Roche). The successful removal of genomic DNA was tested by PCR. RNA was heated at $85^{\circ} \mathrm{C}$ for 10 minutes and reverse transcription was carried out using the SuperScript Reverse Transcriptase kit (Invitrogen) and following the manufacturer's conditions. The $\operatorname{rnp} B$ gene was used as an internal control to normalize the amounts of cDNA in the PCR reactions. The results of the PCRs were visualized in $1-1.5 \%$ agarose gels stained with ethidium bromide in a GelDoc 2000 device (Bio-Rad).

\section{Electrophoretic Mobility Shift Assays (EMSAs)}

Gene promoters were obtained by PCR, using the Anabaena sp. PCC 7120 genome as a template using the primers described in Table S2. To ensure the specific binding of the protein to the studied promoters, the promoter of nifJ (alr1911) gene was used as a competitor DNA in all reactions. Reaction mixtures with a final volume of $20 \mu 1$ contained $50 \mathrm{ng}$ of each promoter, binding buffer $(10 \mathrm{mM}$ bis-Tris $\mathrm{pH} 7.5,40 \mathrm{mM} \mathrm{KCl}$, $2 \mathrm{mM} \mathrm{MgCl} 2 \cdot 6 \mathrm{H}_{2} \mathrm{O}, 5 \%$ glycerol), $0.05 \mathrm{mg} / \mathrm{ml} \mathrm{BSA}, 1 \mathrm{mM}$ DTT, $5 \mu \mathrm{M} \mathrm{ZnSO} \cdot \mathrm{ZH}_{2} \mathrm{O}$ and 100-300 $\mathrm{nM}$ recombinant Zur. Resulting mixtures were incubated for 30 minutes at room temperature and loaded into non-denaturing $6 \%$ polyacrylamide gels. Gels were stained with SYBR®Safe (Invitrogen) and visualized in a GelDoc 2000 device (Bio$\mathrm{Rad})$.

\section{ACKNOWLEDGEMENTS}


509 This work has been supported by grants BFU2012-31458 from MINECO, B18 from

510 Gobierno de Aragón and Obra Social La Caixa. VCS is recipient of a fellowship from

511 Gobierno de Aragón. The authors have no conflict of interest to declare.

512

513

514

515

516

517

518

519

520

521

522

523

524

\section{REFERENCES}

Andrews, S.C., Robinson, A.K., and Rodríguez-Quiñones, F. (2003) Bacterial iron homeostasis. FEMS Microbiology Reviews 27: 215-237.

Banerjee, M., Ballal, A., and Apte, S.K. (2012) Mn-catalase (Alr0998) protects the photosynthetic, nitrogen-fixing cyanobacterium Anabaena PCC7120 from oxidative stress. Environmental Microbiology 14: 2891-2900.

Banerjee, M., Raghavan, P.S., Ballal, A., Rajaram, H., and Apte, S.K. (2013) Oxidative stress management in the filamentous, heterocystous, diazotrophic cyanobacterium, Anabaena PCC7120. Photosynthesis Research 118: 59-70.

Barnett, J.P., Millard, A., Ksibe, A.Z., Scanlan, D.J., Schmid, R., and Blindauer, C.A. (2012) Mining genomes of marine cyanobacteria for elements of zinc homeostasis. Front Microbiol 3: 142.

Beers, R.F., and Sizer, I.W. (1952) A spectrophotmetric method for measuring the breakdown of hydrogen peroxide by catalase. Journal of Biological Chemistry 195: 133-140.

Bihani, S.C., Chakravarty, D., and Ballal, A. (2013) Purification, crystallization and preliminary crystallographic analysis of KatB, a manganese catalase from Anabaena PCC 7120. Acta Crystallographica Section F Structural Biology and Crystallization Communications 69: 1299-1302.

Bonet, B., Corcoll, N., and Guasch, H. (2012) Antioxidant enzyme activities as biomarkers of Zn pollution in fluvial biofilms. Ecotoxicol Environ Saf 80: 172-178. 
535 Botello-Morte, L., Gonzalez, A., Bes, M.T., Peleato, M.L., and Fillat, M.F. (2013)

536 Functional Genomics of Metalloregulators in Cyanobacteria. Genomics of 537 Cyanobacteria 65: 107-156.

538 Buikema, W.J., and Haselkorn, R. (2001) Expression of the Anabaena hetR gene from a

539 copper-regulated promoter leads to heterocyst differentiation under repressing $540 \quad$ conditions. Proceedings of the National Academy of Sciences 98: 2729-2734.

541 Cai, Y., and Wolk, P. (1990) Use of a Conditionally Lethal Gene in Anabaena sp. strain 542 PCC 7120 To Select for Double Recombinants and To Entrap Insertion Sequences. $543 \quad$ Journal of Bacteriology 172: 3138-3145.

544 Cornelis, P., Andrews, S. C., eds. (2010) Iron Uptake and Homeostasis in 545 Microorganisms. Caister Academic Press, Norfolk, UK.

546 Chiang, S.M., and Schellhorn, H.E. (2012) Regulators of oxidative stress response 547 genes in Escherichia coli and their functional conservation in bacteria. Arch Biochem 548 Biophys 525: 161-169.

549 Choi, S., and Bird, A.J. (2014) Zinc'ing sensibly: controlling zinc homeostasis at the $550 \quad$ transcriptional level. Metallomics 6: 1198-1215.

551 Davies, B.H. (1976) Carotenoids. In Chemistry and Biochemistry of Plant Pigments. 552 Goodwin, T.W. (ed). New York: Academic Press, pp. 38-165.

553 Divakaruni, A.V., Loo, R.R.O., Xie, Y., Loo, J.A., and Gober, J.W. (2005) The cell554 shape protein $\mathrm{MreC}$ interacts with extracytoplasmic proteins including cell wall 555 assembly complexes in Caulobacter crescentus. Proceedings of the National Academy 556 of Sciences 102: 18602-18607.

557 Eide, D.J. (2011) The oxidative stress of zinc deficiency. Metallomics 3: 1124-1129.

558 Eijkelkamp, B.A., Morey, J.R., Ween, M.P., Ong, C.L., McEwan, A.G., Paton, J.C., and 559 McDevitt, C.A. (2014) Extracellular zinc competitively inhibits manganese uptake 
560 and compromises oxidative stress management in Streptococcus pneumoniae. PLoS $561 \quad$ One 9: e89427.

562 Elhai, J., Vepritskiy, A., Muro-Pastor, A.M., Flores, E., and Wolk, P. (1997) Reduction 563 of conjugal transfer efficiency by three restriction activities of Anabaena sp. strain 564 PCC 7120. Journal of Bacteriology 179: 1998-2005.

565 Flores, E., and Herrero, A. (2010) Compartmentalized function through cell 566 differentiation in filamentous cyanobacteria. Nat Rev Microbiol 8: 39-50.

567 Fuangthong, M., and Helmann, J.D. (2003) Recognition of DNA by Three Ferric 568 Uptake Regulator (Fur) Homologs in Bacillus subtilis. Journal of Bacteriology 185: $569 \quad 6348-6357$.

570 Gabriel, S.E., and Helmann, J.D. (2009) Contributions of Zur-controlled ribosomal 571 proteins to growth under zinc starvation conditions. J Bacteriol 191: 6116-6122.

572 Glazer, A.N. (1976) Phycocyanins. In Photochemical and Photobiological Reviews. 573 Smith, K.C. (ed). New York: Plenum Press, pp. 71-115.

574 Gonzalez, A., Bes, M.T., Barja, F., Peleato, M.L., and Fillat, M.F. (2010) 575 Overexpression of FurA in Anabaena sp. PCC 7120 Reveals New Targets for This 576 Regulator Involved in Photosynthesis, Iron Uptake and Cellular Morphology. Plant $577 \quad$ and Cell Physiology 51: 1900-1914.

578 González, A., Bes, M.T., Peleato, M.L., and Fillat, M.F. (2011) Unravelling the 579 regulatory function of FurA in Anabaena sp. PCC 7120 through 2-D DIGE proteomic $580 \quad$ analysis. Journal of Proteomics 74: 660-671.

581 González, A., Bes, M.T., Valladares, A., Peleato, M.L., and Fillat, M.F. (2012) FurA is 582 the master regulator of iron homeostasis and modulates the expression of tetrapyrrole 583 biosynthesis genes in Anabaena sp. PCC 7120. Environmental Microbiology 14: $584 \quad 3175-3187$. 
585 Graham, A.I., Sanguinetti, G., Bramall, N., McLeod, C.W., and Poole, R.K. (2012)

586 Dynamics of a starvation-to-surfeit shift: a transcriptomic and modelling analysis of 587 the bacterial response to zinc reveals transient behaviour of the Fur and SoxS 588 regulators. Microbiology 158: 284-292.

589 Hassan, H.M., and Sun, H.-C.H. (1992) Regulatory roles of Fnr, Fur and Arc in 590 expression of manganese-containing superoxide dismutase in Escherichia coli. $591 \quad$ Proceedings of the National Academy of Sciences 89: 3217-3221.

592 Hasset, D.J., Howell, M.L., Ochsner, U.A., Vasil, M.L., Johnson, Z., and Dean, G.E. 593 (1997) An Operon Containing fumC and $\operatorname{sodA}$ Encoding Fumarase C and Manganese 594 Superoxide Dismutase Is Controlled by the Ferric Uptake Regulator in Pseudomonas 595 aeruginosa: fur Mutants Produce Elevated Alginate Levels. Journal of Bacteriology: $596 \quad 1452-1459$.

597 Hernandez, J. (2004) Three fur homologues from Anabaena sp. PCC7120: exploring 598 reciprocal protein-promoter recognition. FEMS Microbiology Letters 236: 275-282.

599 Hernandez, J.A., Pellicer, S., Huang, L., Peleato, M.L., and Fillat, M.F. (2007) FurA 600 modulates gene expression of alr3808, a DpsA homologue in Nostoc (Anabaena) sp. $601 \quad$ PCC7120. FEBS Lett 581: 1351-1356.

602 Hernandez, J.A., Muro-Pastor, A.M., Flores, E., Bes, M.T., Peleato, M.L., and Fillat, 603 M.F. (2006) Identification of a furA cis antisense RNA in the cyanobacterium 604 Anabaena sp. PCC 7120. J Mol Biol 355: 325-334.

605 Kallifidas, D., Pascoe, B., Owen, G.A., Strain-Damerell, C.M., Hong, H.J., and Paget, 606 M.S.B. (2009) The Zinc-Responsive Regulator Zur Controls Expression of the 607 Coelibactin Gene Cluster in Streptomyces coelicolor. Journal of Bacteriology 192: $608 \quad 608-611$. 
609 Latifi, A., Ruiz, M., and Zhang, C.C. (2009) Oxidative stress in cyanobacteria. FEMS $610 \quad$ Microbiol Rev 33: 258-278.

611 Latifi, A., Jeanjean, R., Lemeille, S., Havaux, M., and Zhang, C.C. (2005) Iron 612 Starvation Leads to Oxidative Stress in Anabaena sp. Strain PCC 7120. Journal of 613 Bacteriology 187: 6596-6598.

614 Lee, H.W., Choe, Y.H., Kim, D.K., Jung, S.Y., and Lee, N.G. (2004) Proteomic 615 analysis of a ferric uptake regulator mutant of Helicobacter pylori: Regulation of 616 Helicobacter pylori gene expression by ferric uptake regulator and iron. Proteomics 4: $617 \quad 2014-2027$.

618 Lee, J.-W., and Helmann, J.D. (2007) Functional specialization within the Fur family of 619 metalloregulators. BioMetals 20: 485-499.

620 Lee, M.H., Scherer, M., Rigali, S., and Golden, J.W. (2003) PlmA, a New Member of 621 the GntR Family, Has Plasmid Maintenance Functions in Anabaena sp. Strain PCC 622 7120. Journal of Bacteriology 185: 4315-4325.

623 Li, Y., Qiu, Y., Gao, H., Guo, Z., Han, Y., Song, Y. et al. (2009) Characterization of 624 Zur-dependent genes and direct Zur targets in Yersinia pestis. BMC Microbiology 9: $625 \quad 128$.

626 Lindsay, J.A., and Foster, S.J. (2001) zur: a Zn2+-responsive regulatory element of 627 Staphylococcus aureus. Microbiology 147: 1259-1266.

628 Lopez-Gomollon, S., Hernandez, J.A., Wolk, C.P., Peleato, M.L., and Fillat, M.F. 629 (2007a) Expression of furA is modulated by NtcA and strongly enhanced in 630 heterocysts of Anabaena sp. PCC 7120. Microbiology 153: 42-50.

631 Lopez-Gomollon, S., Hernandez, J.A., Pellicer, S., Angarica, V.E., Peleato, M.L., and 632 Fillat, M.F. (2007b) Cross-talk between iron and nitrogen regulatory networks in 
633 Anabaena (Nostoc) sp. PCC 7120: identification of overlapping genes in FurA and $634 \quad$ NtcA regulons. J Mol Biol 374: 267-281.

635 López-Gomollón, S., Sevilla, E., Bes, M.T., Peleato, M.L., and Fillat, María F. (2009) 636 New insights into the role of Fur proteins: FurB (All2473) from Anabaena protects 637 DNA and increases cell survival under oxidative stress. Biochemical Journal 418: 638201.

639 Ma, Z., Jacobsen, F.E., and Giedroc, D.P. (2009) Coordination chemistry of bacterial 640 metal transport and sensing. Chem Rev 109: 4644-4681.

641 Maciag, A., Dainese, E., Rodriguez, G.M., Milano, A., Provvedi, R., Pasca, M.R. et al. 642 (2006) Global Analysis of the Mycobacterium tuberculosis Zur (FurB) Regulon. 643 Journal of Bacteriology 189: 730-740.

644 Maret, W. (2006) Zinc coordination environments in proteins as redox sensors and 645 signal transducers. Antioxid Redox Signal 8: 1419-1441.

646 Mills, D.A., Schmidt, B., Hiser, C., Westley, E., and Ferguson-Miller, S. (2002) 647 Membrane Potential-controlled Inhibition of Cytochrome c Oxidase By Zinc. The $648 \quad$ Journal of Biological Chemistry 277: 14894-14901.

649 Napolitano, M., Rubio, M.A., Santamaria-Gomez, J., Olmedo-Verd, E., Robinson, N.J., 650 and Luque, I. (2012) Characterization of the Response to Zinc Deficiency in the 651 Cyanobacterium Anabaena sp. Strain PCC 7120. Journal of Bacteriology 194: 24266522436.

653 Nicolaisen, K., Moslavac, S., Samborski, A., Valdebenito, M., Hantke, K., Maldener, I. 654 et al. (2008) Alr0397 Is an Outer Membrane Transporter for the Siderophore 655 Schizokinen in Anabaena sp. Strain PCC 7120. Journal of Bacteriology 190: 75006567507. 
657 Olmedo-Verd, E., Flores, E., Herrero, A., and Muro-Pastor, A.M. (2005) HetR658 Dependent and -Independent Expression of Heterocyst-Related Genes in an Anabaena 659 Strain Overproducing the NtcA Transcription Factor. Journal of Bacteriology 187: $660 \quad 1985-1991$.

661 Panina, E.M., Mironov, A.A., and Gelfand, M.S. (2003) Comparative genomics of 662 bacterial zinc regulons: enhanced ion transport, pathogenesis, and rearrangement of 663 ribosomal proteins. Proc Natl Acad Sci U S A 100: 9912-9917.

664 Patzer, S.I. (2000) The Zinc-responsive Regulator Zur and Its Control of the znu Gene 665 Cluster Encoding the ZnuABC Zinc Uptake System in Escherichia coli. Journal of 666 Biological Chemistry 275: 24321-24332.

667 Rippka, R., Deruelles, J., Waterbury, J.B., Herdman, M., and Stanier, R.Y. (1978) 668 Generic assignments, strain histories and propierties of pure cultures of cyanobacteria. 669 Journal of General Microbiology 111: 1-61.

670 Sankaran, B., Bonnett, S.A., Shah, K., Gabriel, S., Reddy, R., Schimmel, P. et al. (2009) 671 Zinc-independent folate biosynthesis: genetic, biochemical, and structural 672 investigations reveal new metal dependence for GTP cyclohydrolase IB. J Bacteriol 673 191: 6936-6949.

674 Shcolnick, S., Summerfield, T.C., Reytman, L., Sherman, L.A., and Keren, N. (2009) 675 The mechanism of iron homeostasis in the unicellular cyanobacterium Synechocystis 676 sp. PCC 6803 and its relationship to oxidative stress. Plant Physiol 150: 2045-2056.

677 Singh, S.P., and Montgomery, B.L. (2011) Determining cell shape: adaptive regulation 678 of cyanobacterial cellular differentiation and morphology. Trends in Microbiology 19: $679 \quad 278-285$.

680 Stein, J.R. (1973) Handbook of Phycological Methods: Culture Methods and Growth 681 Measurements. New York: Cambridge University Press. 
682 Stohs, S.J., and Bagchi, D. (1995) Oxidative mechanisms in the toxicity of metal ions. $683 \quad$ Free Radic Biol Med 18: 321-336.

684 Thurman, R.G., Ley, H.G., and Scholz, R. (1972) Hepatic microsomal ethanol 685 oxidation. Hydrogen peroxide formation and the role of catalase. Eur J Biochem 25: $686 \quad 420-430$.

687 Winterbourn, C.C., Hawkins, R.E., Brian, M., and Carrell, R.W. (1975) Estimation of 688 Red-Cell Superoxide-Dismutase Activity. Journal of Laboratory and Clinical $689 \quad$ Medicine 85: 337-341.

690 Yingping, F., Lemeille, S., Talla, E., Janicki, A., Denis, Y., Zhang, C.-C., and Latifi, A. 691 (2014) Unravelling the cross-talk between iron starvation and oxidative stress 692 responses highlights the key role of PerR (alr0957) in peroxide signalling in the 693 cyanobacterium Nostoc PCC 7120. Environmental Microbiology Reports: 694 DOI: $10.1111 / 1758-2229.12157$.

695

696

697 
699

700

701

702

\section{Figure 1. Photoautotrophic growth of the cyanobacterial strains used in this work.} Cyanobacterial growth in BG11 at standard culture conditions was analyzed by measuring optical density at $750 \mathrm{~nm}$. Every measure was performed three times and the standard deviation, $\mathrm{SD}$, is represented by the vertical bars.

\section{Figure 2. Analyses of cell surface and culture sedimentation. A) Scanning electron} microscopy photographs from exponentially growing cultures. The scale is indicated in the horizontal bar. B) Sedimentation of the strains at 24 hours. The exponentially growing strains were cultured with no shaking and a constant illumination of 50 $\mu \mathrm{E} / \mathrm{m}^{2} \cdot \mathrm{s}$. Photographs were taken after 24 hours.

Figure 3. Oxidative stress tolerance against hydrogen peroxide. A) Photograph of the microtiter plate containing the cyanobacterial strains with increasing hydrogen peroxide concentrations. B) Estimation of the chlorosis by reading the OD of the microtiter plate at $620 \mathrm{~nm}$. The SD is represented by the vertical bars.

\section{Figure 4. Superoxide dismutase and catalase activities in crude extracts of the} cyanobacterial strains. A) Superoxide dismutase activity. B) Catalase activity. Activities are expressed as Units per milligram of total proteins in the extract. Every measure was performed three times and the SD is represented by the vertical bars.

Figure 5. Hydrogen peroxide content in crude extracts of the cyanobacterial

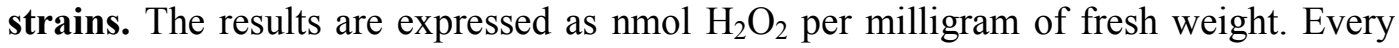
measure was performed three times and the SD is represented by the vertical bars. 
724 Figure 6. Semi-quantitative RT-PCR analyses. Total RNA was isolated from

725 exponentially growing cultures. The $\operatorname{rnpB}$ gene was used as housekeeping to normalize

726 the amount of cDNA in each sample. Please note that the images of the gels were

727 coloured inverted in order to increase the sensitivity of detection.

728

729

730

731

732

733

734

735

736

737

738

739

740

741

742

743

744

745

746

747

748

749

\section{Figure 7. Electrophoretic Mobility Shift Assays with recombinant Zur protein. nifJ} promoter was used as a competitor in all the assays and is marked with an arrow on the left. Lane 1 in all gels contained free promoters. Lanes 2-4 contained the promoters with Zur at final concentrations of 100, 200 and $300 \mathrm{nM}$ respectively. The first gel of each row contains the controls with the all4725 promoter and the nifJ one. The absence (-) or presence of $250 \mathrm{nM} \mathrm{Zur} \mathrm{(+)} \mathrm{in} \mathrm{the} \mathrm{controls} \mathrm{is} \mathrm{indicated} \mathrm{above} \mathrm{the} \mathrm{lanes.} \mathrm{Optimal}$ conditions ( $5 \mu \mathrm{M} \mathrm{ZnSO}_{4}$ and $1 \mathrm{mM}$ DTT) were used in all the assays. Note that the images of the gels were coloured inverted in order to increase the sensitivity of detection.

\section{TABLES}

Table 1. Percentage of photosynthetic pigments in the cyanobacterial strains. Pigments were measured at the exponential phase of growth. The results are the average of three determinations $\pm \mathrm{SD}$ and are expressed as the percentage related to total soluble protein content.

Table 2. Photosynthetic and respiratory activities. Activities were measured at the exponential phase of growth. The results are the average of two determinations $\pm \mathrm{SD}$ and are expressed as $\mu \mathrm{mol} \mathrm{O}_{2} \cdot \mathrm{min}^{-1} \cdot \mathrm{mg} \mathrm{Chla}{ }^{-1}$. 
750 Table 3. Relative induction ratio of selected genes in relation to the wild type

751 strain. Data are derived from the results of the semi quantitative RT-PCR analyses.

752 Intensity of the DNA bands in the agarose gels was determined with ImageJ software.

753 Values are means of two independent determinations \pm SD.

754

755 SUPPLEMENTARY MATERIAL

756

Figure S1. Verification of zur deletion and overexpression by Western blot. A) Verification of zur deletion. Lanes contain $30 \mu \mathrm{g}$ of Anabaena sp. PCC 7120 and Anabaena $\Delta z u r$ protein extracts respectively. B) Verification of zur overexpression. Lanes contain $6.5 \mu \mathrm{g}$ of protein extracts from Anabaena sp. PCC 7120, zuroverexpressing strain (VCS2770) and Anabaena $\Delta z u r$ respectively. Molecular weight of

762 protein marker bands is expressed in $\mathrm{kDa}$.

763

764

765

766

767
Table S1. Bacterial strains used in this study.

Table S2. Oligonucleotides used in this study. 


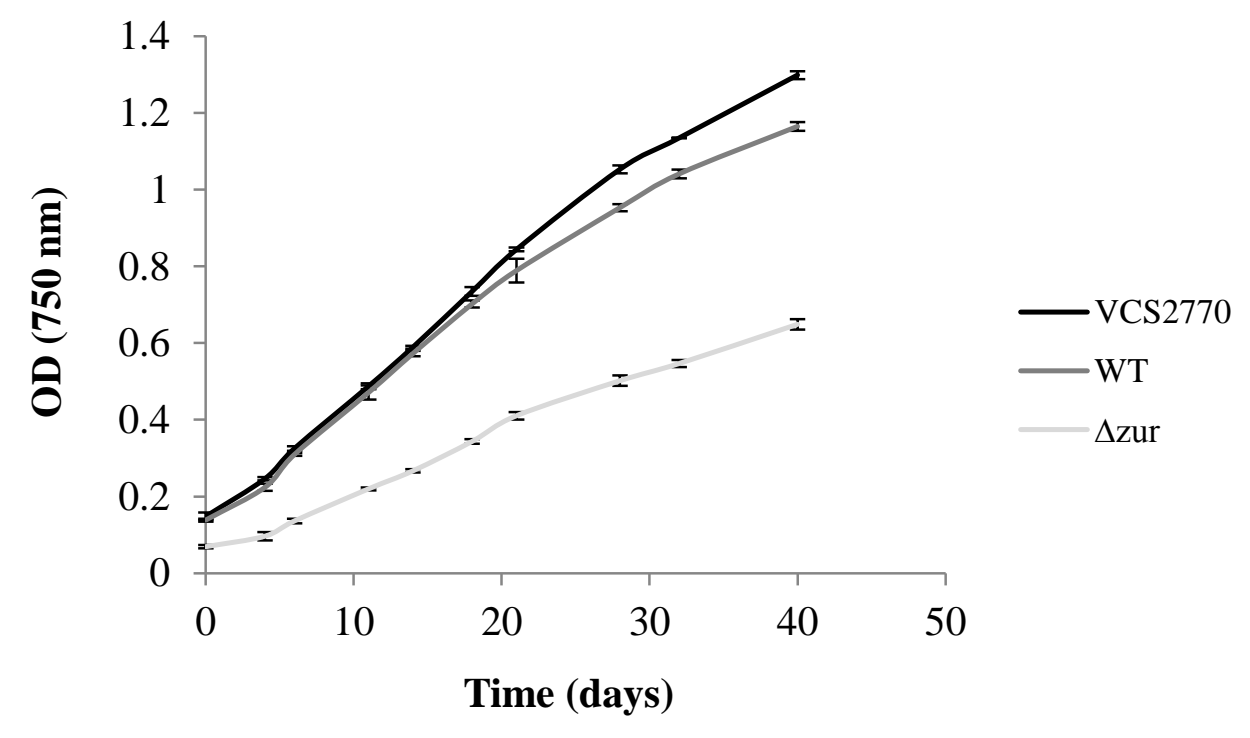




\section{Figurper21 1}

A

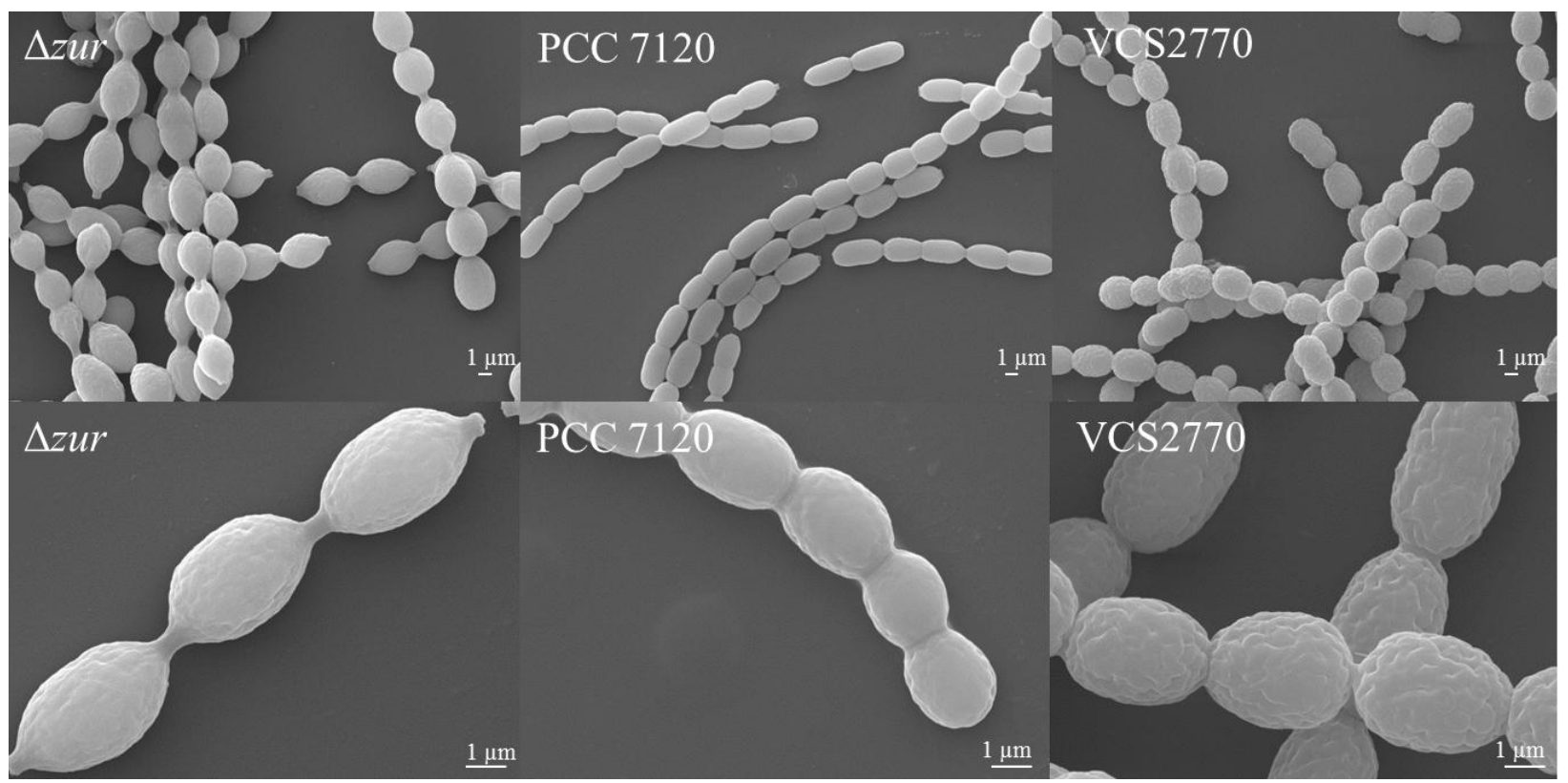

B

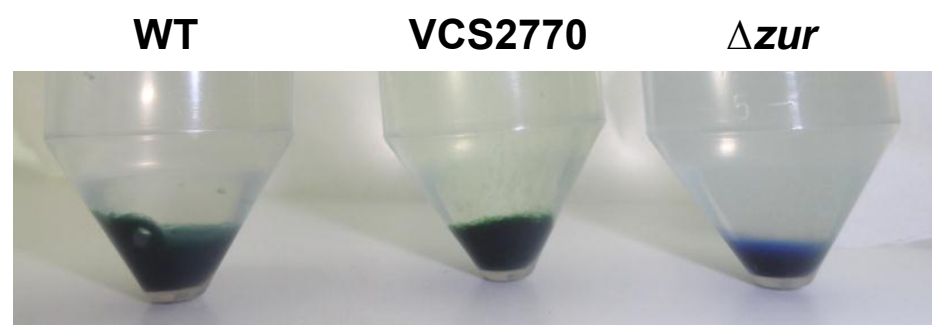


A

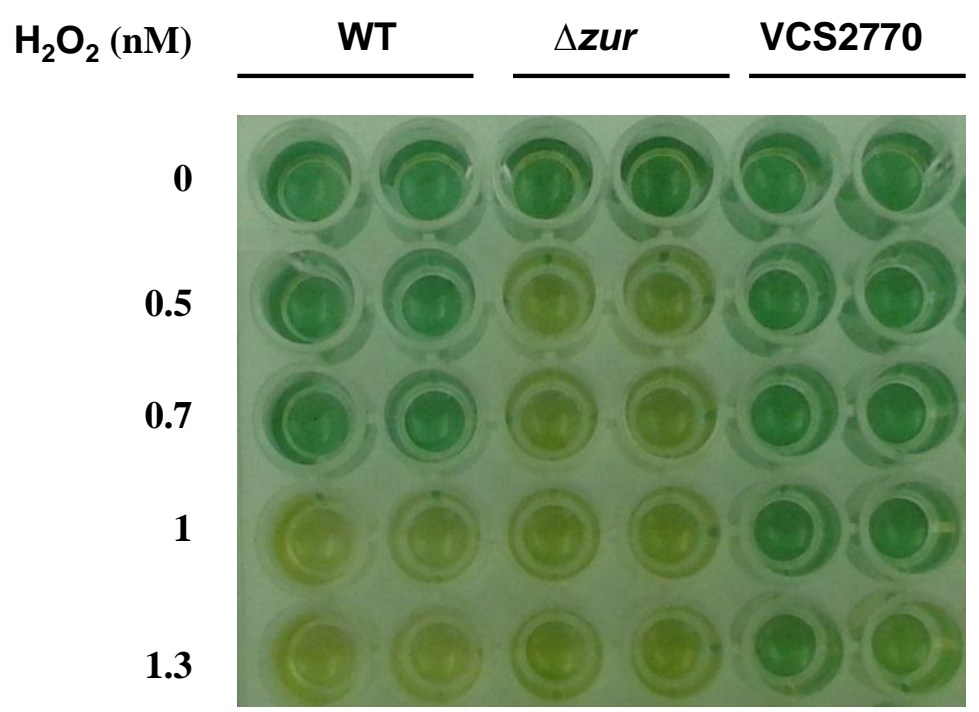

B

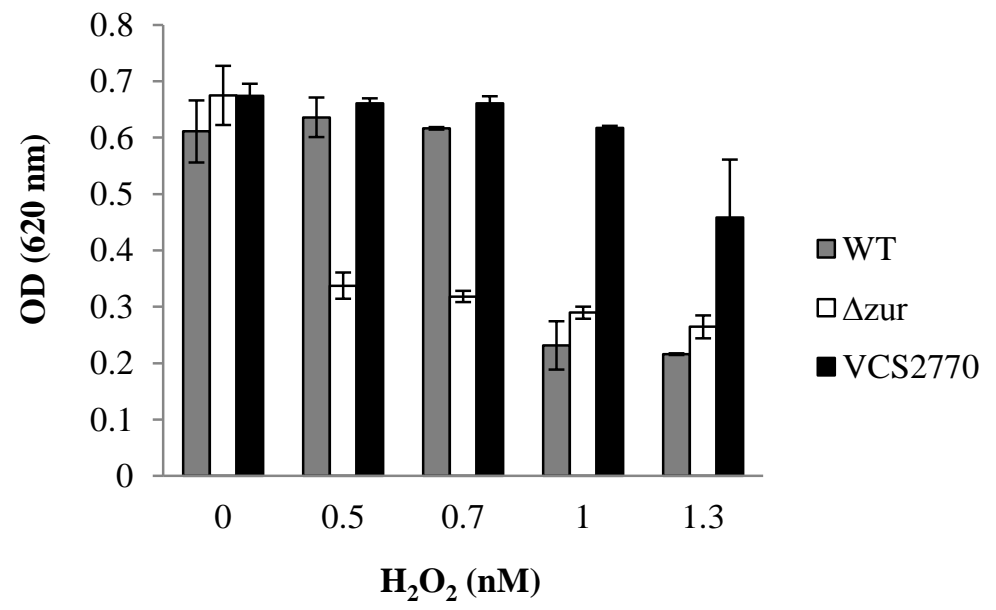




\section{Pigurfet41}

A

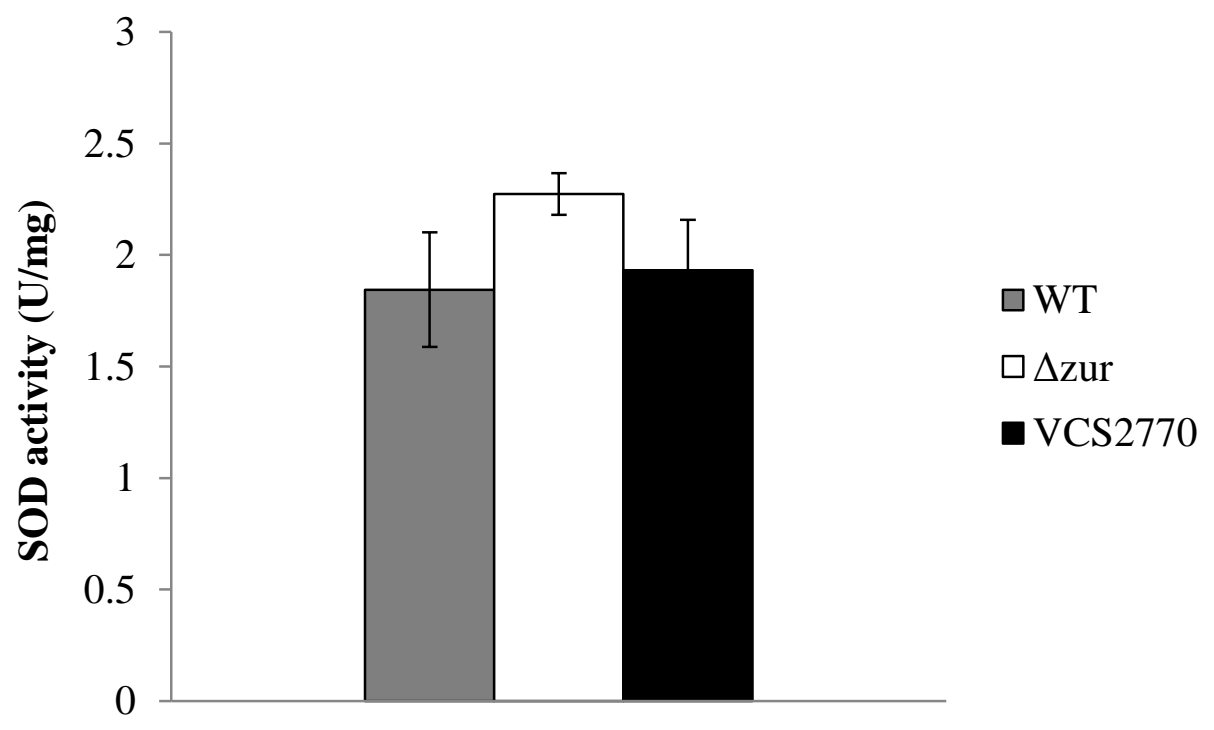

B

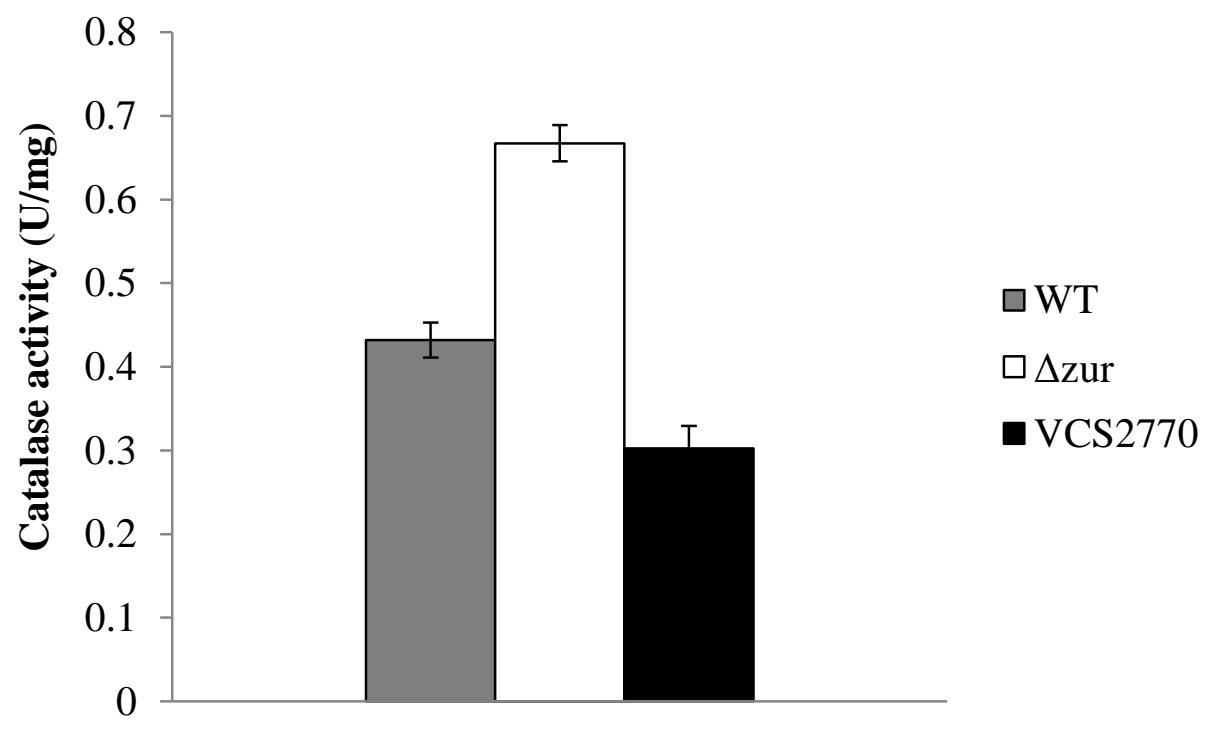




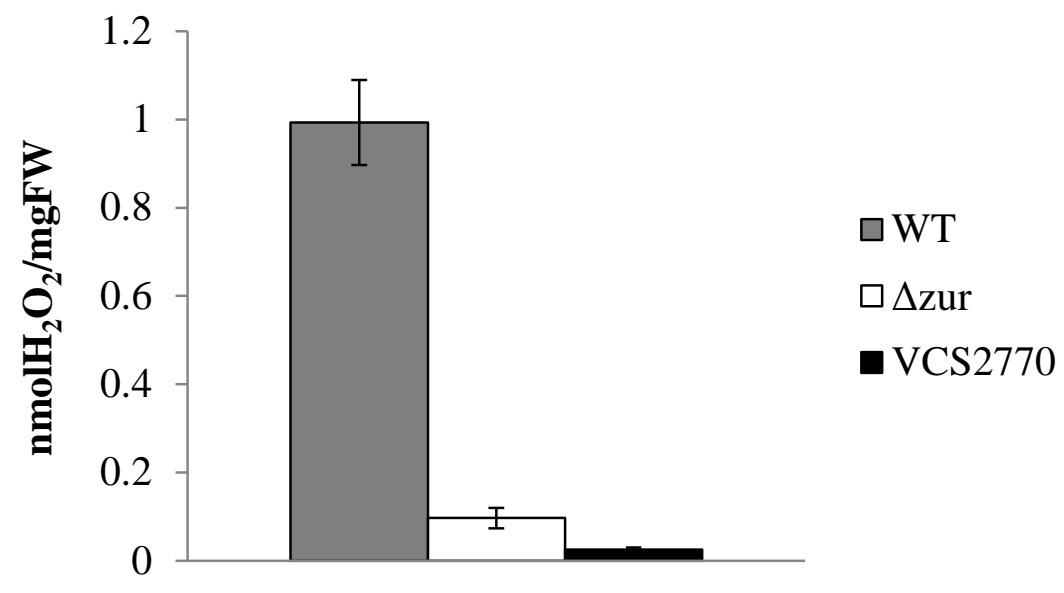




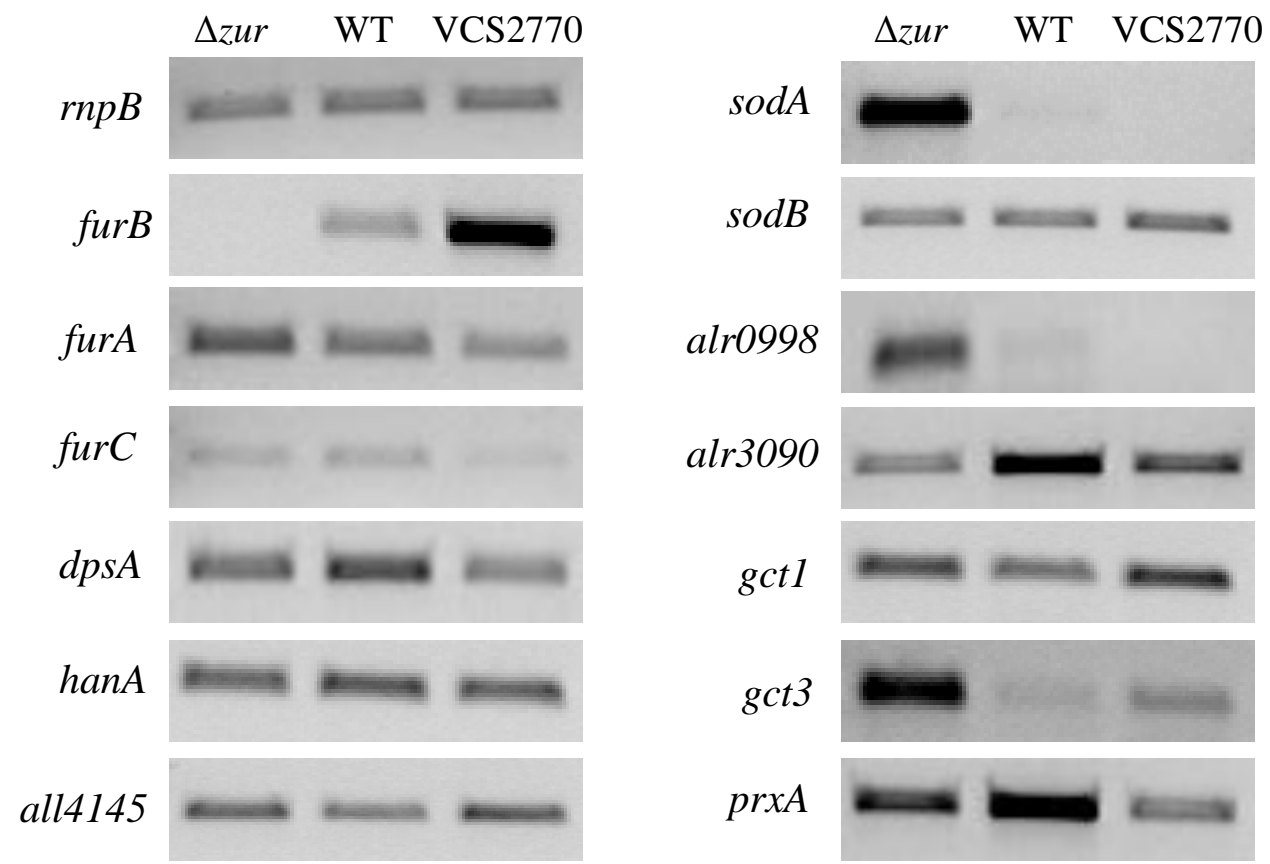



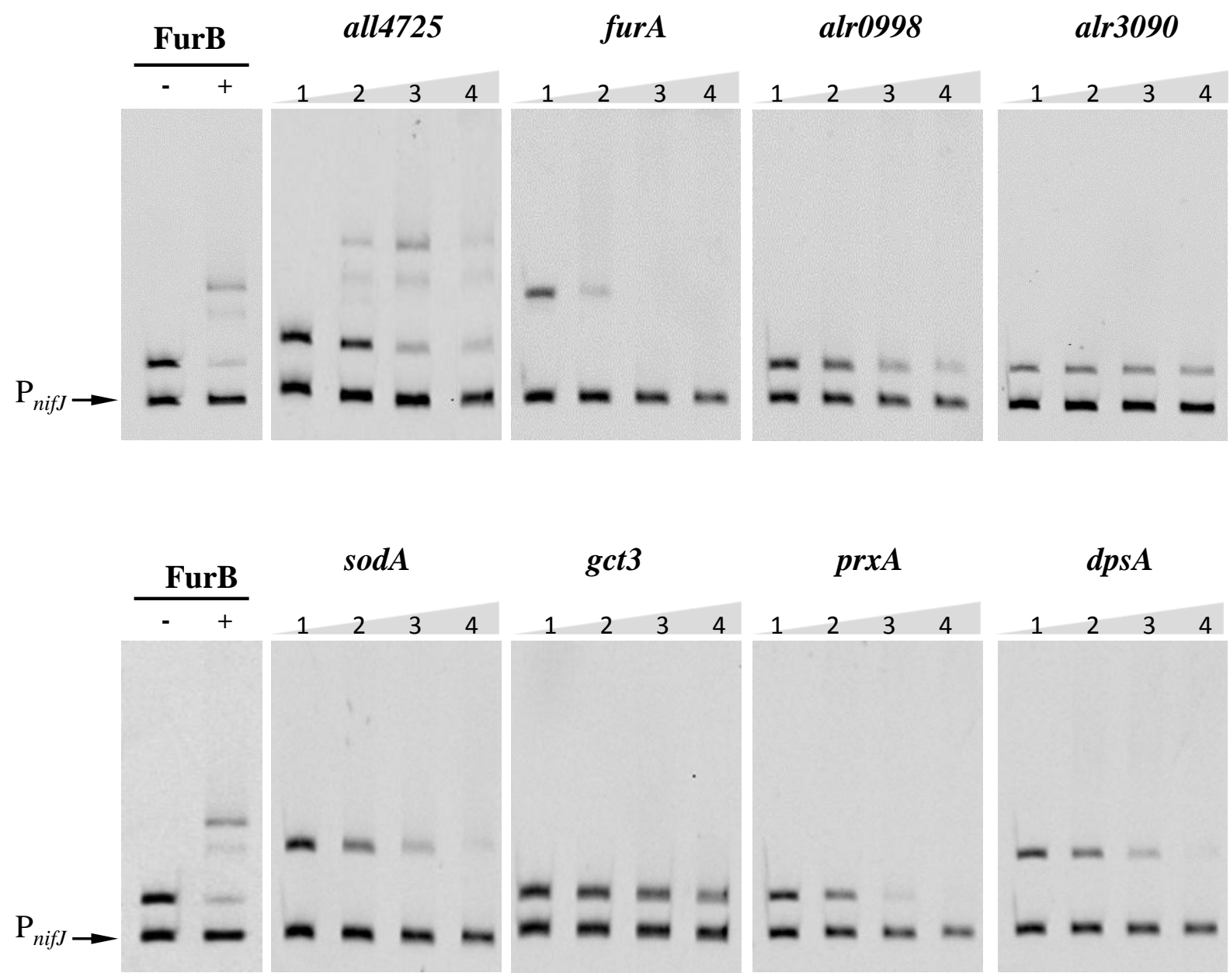
Table 1

\begin{tabular}{lccc}
\hline Pigments & \multicolumn{3}{c}{ Strains } \\
\cline { 2 - 4 } & WT & $\Delta$ zur & VCS2770 \\
\cline { 2 - 4 } Chlorophyll $a$ & $2.20 \pm 0.14$ & $2.56 \pm 0.61$ & $4.06 \pm 0.45$ \\
Carotenoids & $0.050 \pm 0.00$ & $0.034 \pm 0.00$ & $0.052 \pm 0.00$ \\
Phycobiliproteins & $24.56 \pm 0.03$ & $24.64 \pm 0.45$ & $27.60 \pm 0.42$ \\
\hline
\end{tabular}


Table 2

\begin{tabular}{lccc}
\hline Strain & Photosynthesis & Respiration & $\begin{array}{c}\text { Total oxygen } \\
\text { evolution }\end{array}$ \\
\hline WT & $4.76 \pm 0.17$ & $0.68 \pm 0.17$ & $5.44 \pm 0.17$ \\
$\Delta \boldsymbol{z u r}$ & $4.29 \pm 0.22$ & $0.82 \pm 0.15$ & $5.11 \pm 0.37$ \\
VCS2770 & $4.69 \pm 0.28$ & $0.75 \pm 0.16$ & $5.81 \pm 0.44$ \\
\hline
\end{tabular}




\begin{tabular}{llcc}
\hline Gene ID $^{\text {a }}$ & Protein description $^{\text {a }}$ & $\boldsymbol{\Delta z \boldsymbol { z } / / \mathbf { W T }}$ & VCS2770/WT \\
\hline all2473 & Ferric Uptake regulator B, FurB/Zur & 0 & $4.69 \pm 0.23$ \\
all1691 & Ferric Uptake regulator A, FurA & $1.25 \pm 0.01$ & $0.66 \pm 0.01$ \\
alr0957 & Ferric Uptake regulator C, FurC & $1.16 \pm 0.17$ & $0.66 \pm 0.04$ \\
all0070 & Manganese superoxide dismutase, SodA & $11.62 \pm 0.27$ & 0 \\
alr2938 & Iron superoxide dismutase, SodB & $0.94 \pm 0.01$ & $1.27 \pm 0.01$ \\
alr0998 & Manganese catalase & $4.12 \pm 0.19$ & 0 \\
alr3090 & Manganese catalase & $0.29 \pm 0.01$ & $0.56 \pm 0.05$ \\
alr3183 & Peroxiredoxin, PrxQ-B, Gct1 & $1.36 \pm 0.02$ & $1.56 \pm 0.01$ \\
all2375 & Peroxiredoxin, PrxQ-C, Gct3 & $7.64 \pm 0.14$ & $2.34 \pm 0.06$ \\
alr4641 & Peroxiredoxin, PrxA & $0.52 \pm 0.01$ & $0.35 \pm 0.01$ \\
alr3808 & DpsA & $0.75 \pm 0.01$ & $0.52 \pm 0.01$ \\
asr3935 & DNA binding protein HU & $0.83 \pm 0.01$ & $0.89 \pm 0.02$ \\
all4145 & Probable DNA binding stress protein & $1.38 \pm 0.08$ & $1.31 \pm 0.14$ \\
\hline
\end{tabular}

a. Gene identification and protein description according to the cyanobacteria genome database Cyanobase (http://genome.microbedb.jp/cyanobase/) 